\title{
NERACA AIR LAHAN GAMBUT YANG DITANAMI KELAPA SAWIT DI KABUPATEN SERUYAN, KALIMANTAN TENGAH
}

\section{Water Balance in Cultivated Peatlands with Oil Palm in Seruyan Regency, Central Kalimantan}

\author{
Suria Darma Tarigan* \\ Departemen Ilmu Tanah dan Sumberdaya Lahan, Fakultas Pertanian, IPB, J1. Meranti Kampus IPB Darmaga \\ Bogor 16680
}

\begin{abstract}
In order to optimally manage water level during dry season, it is necessary to analyze components of water balance in peatlands including: a) Pre-storage, b) Evapotranspiration, c) Drainage pore space, d) Hydraulic conductivity and d) Drainage discharge. Aim of the research was to analyze water balance components which can be used to determine optimal drainage management in cultivated peatlands with oil palm. Steady-State Hooghoudt equation was used to determine related parameter of water balance components in relation to drainage system. Field research was conducted in oil palm plantation area in Seruyan District, Central Kalimantan. During dry season (July-September), evapotranspiration reached value of 386 $\mathrm{mm}$ exceeded rainfall amount of $311 \mathrm{~mm}$. Drain discharge in this time period was $90 \mathrm{~mm}$ or $1 \mathrm{~mm}$ day-1. Based on these values, water deficit amounted to $25 \mathrm{~mm}$ occurred in the area. When the drain spacing was increased from $30 \mathrm{~m}$ to $50 \mathrm{~m}$, water surplus occurred as much as $34 \mathrm{~mm}$. But, it only contributed to the rise of $2.3 \mathrm{~cm}$ water level from existing one which of $40-50 \mathrm{~cm}$. To reduce decrease of water level during dry season, water surplus during transition from wet to dry season should be conserved (pre-storage). Besides, drain discharge should be minimized by using broader distance and use of cascaded stoplog in tertiary drainage systems.
\end{abstract}

Keywords: Drainage channel distance, pre-storage, water balance, water deficit, water level

\begin{abstract}
ABSTRAK
Penurunan muka air pada lahan gambut memicu oksidasi dan subsiden, khususnya pada musim kemarau. Agar dampak penurunan muka air dapat dikelola dengan baik, maka perlu dikaji besaran komponen neraca air (water balance) yang meliputi: a) Pre-storage, b) Evapotranspirasi, c) Ruang pori drainase, d) Konduktivitas hidrolik dan e) Drainase. Penelitian ini bertujuan mengkaji komponen neraca air tersebut pada lahan gambut yang ditanami kelapa sawit yang dapat digunakan untuk menetapkan pengelolaan drainase yang optimal. Metodologi yang digunakan dalam perhitungan kedua komponen neraca air adalah persamaan Hooghoudt Steady-State Approach yang diverifikasi dengan pengukuran data lapang terkait tinggi muka air dengan menggunakan piezometer. Penelitian lapang dilakukan pada perkebunan kelapa sawit di Kabupaten Seruyan, Kalimantan Tengah. Selama musim kemarau (Juli-September), evapotranspirasi mencapai 386 mm yang melebihi besaran curah hujan $(311 \mathrm{~mm})$. Jumlah air drainase pada periode ini adalah $90 \mathrm{~mm}$ atau $1 \mathrm{~mm}$ hari $^{-1}$. Berdasarkan nilai-nilai tersebut terdapat defisit air sebesar $25 \mathrm{~mm}$ selama periode musim kemarau. Jika jarak saluran drainase ditingkatkan dari $30 \mathrm{~m}$ menjadi $50 \mathrm{~mm}$, maka terjadi surplus neraca air sebesar $34 \mathrm{~mm}$. Namun surplus tersebut hanya mampu menaikan muka air tanah sebesar $2.3 \mathrm{~cm}$ dari kondisi awal yang berada pada kedalaman 40-50 cm. Dalam rangka menghambat penurunan muka air pada musim kemarau maka pada masa transisi dari musim penghujan ke musim kemarau perlu dilakukan konservasi air melalui peningkatan pre-storage. Di samping itu kehilangan air drainase perlu ditekan seminim mungkin melalui pengaturan jarak saluran drainase dan penggunaan cascaded stop-log pada sistem saluran tersier.
\end{abstract}

Kata kunci: Jarak saluran drainase, pre-storage, neraca air, defisit air, muka air

\section{PENDAHULUAN}

Menurut Badrun (2010) dan ICALRD (2010) pada Tahun 2009 seluas 131,000 ha dari 871,000 ha (15\%) kebun sawit di Kalimantan Tengah berada pada tanah gambut. Sementara itu seluas 130,000 ha dari 499,000 ha
(26\%) kebun sawit di Kalimantan Barat ditanam pada tanah gambut.

Menurut Sabiham (2010), pemanfaatan lahan gambut sebagai perkebunan kelapa sawit perlu memperhatikan prinsip-prinsip pengelolaan air yang baik. Pada dasarnya gambut tidak boleh tergenang dalam jangka 
waktu lama untuk mendukung pertumbuhan tanaman, namun juga tidak boleh terlalu kering agar gambut tidak menjadi kering tidak-balik (irreversible drying) dan membentuk pasir semu (pseudo-sand). Oleh karena itu pada titik-titik tertentu saluran drainase perlu dibuat pintu air, sehingga mampu mengatur muka air tanah di lahan pertanaman berkisar antara 25-40 cm (Sabiham, 2010).

Menurut Ritzema (2007), desain saluran drainase yang dibuat selama ini berorientasi kepada pembuangan kelebihan air tanpa batas (unrestricted drainage) pada musim penghujan. Hal ini dilakukan agar pertumbuhan akar tanaman dapat kondusif. Pada umumnya desain sistem drainase tersebut belum mempertimbangkan kemungkinan konservasi air pada musim kemarau. Walaupun musim kemarau umumnya berlangsung hanya selama 3 bulan, besar kemungkinan proses oksidasi dan subsidensi berlangsung sangat intensif pada kurun waktu tersebut karena evapotranspirasi melebihi curah hujan. Menurut Noor (2010), pengelolaan air mikro di lahan gambut memerlukan pembuangan air pada musim hujan dan penahanan air pada musim kemarau.

Perlu ada pergeseran paradigma dalam membuat desain saluran dari desain pembuangan kelebihan air tanpa batas (unrestricted drainage) ke pengelolaan air yang berfungsi ganda yaitu untuk pembuangan kelebihan air pada musim penghujan dan sekaligus juga untuk konservasi air pada musim kemarau. Salah satu cara melakukan konservasi air untuk musim kemarau adalah menyimpan kelebihan air pada masa transisi musim hujan ke musim kemarau sebagai pre-storage untuk musim kemarau. Kelebihan air ini dapat disimpan dengan membuat sistem saluran dengan desain cascaded stop-log (Ritzema, 2007).

Penelitian ini bertujuan mengkaji komponen neraca air pada lahan gambut yang ditanami kelapa sawit untuk kegunaan perencanaan saluran drainase.

\section{BAHAN DAN METODE}

\section{Waktu dan Lokasi Penelitian}

Penetapan evapotranspirasi dilakukan dengan menggunakan data piezometer yang diukur pada musim kemarau Tahun 2009, sedangkan penelitian untuk ruang pori drainase $(\boldsymbol{\mu})$ dilakukan dengan menggunakan data musim hujan Tahun 2010. Lokasi penelitian adalah lahan gambut yang ditanami kelapa sawit berumur 7 tahun di Desa Medangsari dan Tanjung Paring, Kabupaten Seruyan, Kalimantan Tengah dengan kedalaman gambut $>3 \mathrm{~m}$ dan kematangan umumnya hemist - saprist.

\section{Peralatan}

Peralatan yang digunakan pada penelitian ini adalah piezometer, ombrometer, bor gambut, dan meteran pengukur kedalaman dan panjang saluran.

\section{Metode}

Komponen neraca air pada lahan gambut yang terkait dengan jarak dan dimensi saluran dianalisis dengan metode Steady-State Hooghoudt. Pada metode ini curah hujan dan perubahan tinggi muka air dihitung dalam interval yang tetap, yaitu mingguan. Pada interval satu minggu tersebut besaran curah hujan dan tinggi muka air dianggap konstan.

\section{Tinggi Muka Air}

Tinggi muka air diukur dengan menggunakan piezometer yang dipasang pada tengah blok tanaman berukuran $300 \mathrm{~m}$ x $1000 \mathrm{~m}$. Pembacaan piezometer dilakukan setiap interval satu minggu. Piezometer terbuat dari pipa PVC berukuran 2.5 inci yang dipasang pada lubang yang dibuat pada lahan gambut. Piezometer perlu ditera setiap bulan karena besar kemungkinan gambut mengalami keamblesan sehingga tinggi referensi terhadap permukaan berubah.

\section{Curah Hujan}

Curah hujan diukur dengan menggunakan Ombrometer yang dipasang sedekat mungkin dengan piezometer. Data curah hujan yang diperoleh adalah data harian.

\section{Perhitungan Neraca Air}

Neraca air lainnya di kebun kelapa sawit ditentukan dengan menggunakan prinsip konservasi massa seperti di bawah ini.

$$
\begin{aligned}
& E a=R-q-\left(h_{t}-h_{t-1}\right) \mu \\
& \mathrm{Ea} \quad=\text { Evapotranspirasi aktual }(\mathrm{mm}) \\
& \mathrm{h}=\text { = Beda tinggi muka air di saluran tersier dan titik } \\
& \text { piezometer } \\
& \mathrm{R}=\text { Curah hujan }(\mathrm{mm}) \\
& \mathrm{q}=\text { Drain discharge }\left(\mathrm{mm} \mathrm{hari}^{-1}\right) \\
& \mu \quad=\text { Ruang pori drainase }
\end{aligned}
$$

\section{Ruang Pori Drainase $(\mu)$}

Ruang pori drainase menunjukkan rasio jumlah air yang berkontribusi menaikkan tinggi muka air pada lahan gambut. Ruang pori drainase bernilai diantara $0-1$. Semakin tinggi nilai $\mu$, maka semakin kecil proporsi kenaikan tinggi muka air akibat curah hujan tertentu. Pori drainase dihitung dengan membandingkan jumlah curah hujan yang jatuh dan kenaikan tinggi muka air pada piezometer. Data yang digunakan untuk perhitungan pori drainase adalah data piezometer pada musim penghujan 2010. Data curah hujan yang dipilih adalah data dengan kejadian hujan yang paling mendekati waktu piezometer reading.

\section{Tinggi Muka Air (h)}

Data tinggi muka air diukur dengan piezometer. Piozemeter terletak persis di tengah-tengah blok tanaman (Gambar 1). Data piezometer dikumpulkan dari 2 lokasi yang berbeda, yaitu di Tj. Paring dan Medangsari, Kabupaten Seruyan, Kalimantan Tengah. Pada setiap lokasi data tinggi muka air diambil rata-rata data dari 8 blok berbeda namun saling berdekatan. 


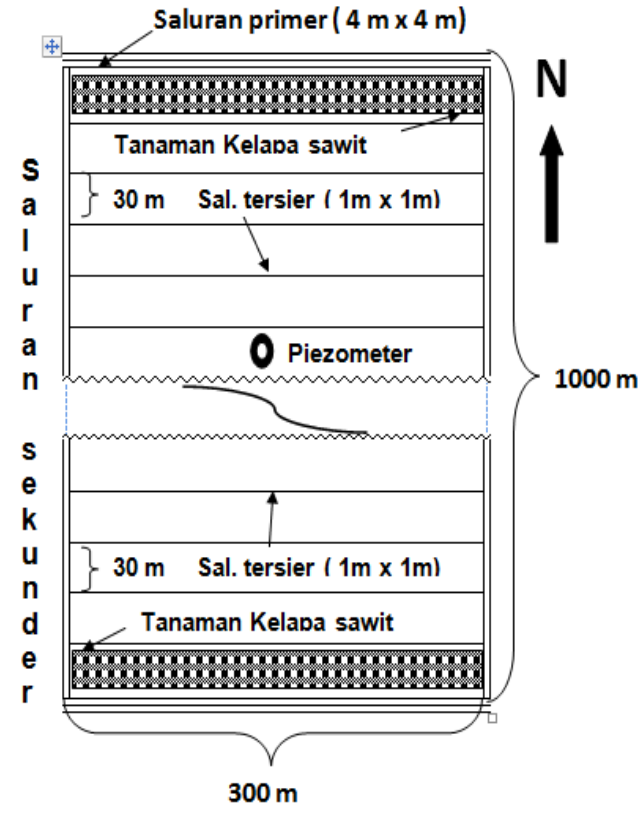

Gambar 1. Posisi piezometer dan ukuran saluran pada tengah blok tanaman yang berukuran (300 m x $1000 \mathrm{~m})$

\section{Drain Discharge (q)}

Drain discharge (Gambar 2) yang merupakan salah satu komponen neraca air di lahan gambut dihitung berdasarkan persamaan Hooghoudt (ILRI, 1994) adalah sebagai berikut:

$$
q=\frac{8 \mathrm{Kdh}+4 \mathrm{Kh}^{2}}{\mathrm{~L}^{2}}
$$

Dimana

$\mathrm{h}=$ Beda tinggi muka air di saluran tersier dan titik piezometer $(\mathrm{m})$

$\mathrm{K}=$ Konduktivitas hidrolik $\left(\mathrm{m}\right.$ hari $\left.^{-1}\right)$

$\mathrm{d}=$ Kedalaman ekivalen lapisan dibawah level saluran drainase $(\mathrm{m})$

$\mathrm{q}=$ Drain discharge $\left(\mathrm{m} \mathrm{hari}^{-1}\right)$

$\mathrm{L}=$ Jarak saluran drainase $(\mathrm{m})$

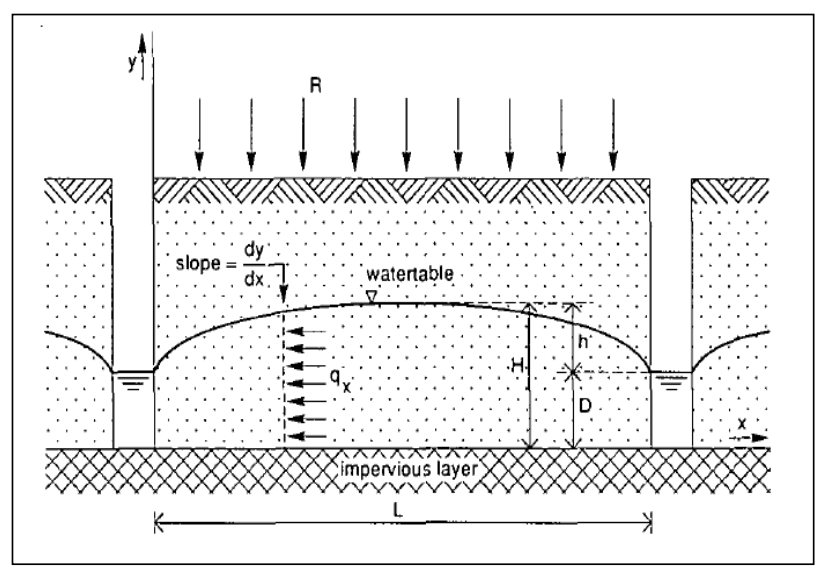

(Sumber : ILRI Publ. Nr. 16)

Gambar 2. Sketsa parameter yang digunakan pada persamaan hooghoudt
HASIL DAN PEMBAHASAN

\section{Fluktuasi Tinggi Muka Air di Perkebunan Kelapa Sawit}

Pengaturan tinggi muka air tersebut dilakukan dengan membuat sistem saluran drainase pada lahan gambut yang berfungsi membuang kelebihan air pada saat musim hujan. Secara umum terdapat kombinasi 3 jenis saluran pada perkebunan kelapa sawit, yaitu saluran primer, sekunder dan tersier. Saluran primer, sekunder dan tersier berukuran berturut-turut adalah $4 \mathrm{~m} \times 4 \mathrm{~m}, 2 \mathrm{~m} \times 2 \mathrm{~m}$ dan $1 \mathrm{~m} \times 1 \mathrm{~m}$.

Tinggi muka air pada saluran sekunder umumnya dipertahankan pada kedalaman $60-70 \mathrm{~cm}$ pada musim penghujan. Mengingat bentuk muka air rata-rata pada lahan gambut yang melengkung (sesuai jarak lokasi dari saluran), maka muka air pada lahan gambut umumnya lebih dangkal berkisar diantara 40-50 cm. Selama ini desain saluran drainase semata-mata berorientasi kepada fungsinya sebagai sarana untuk membuang kelebihan air dari lahan gambut agar pertumbuhan tanaman tidak terganggu oleh genangan air. Desain tersebut belum sepenuhnya mempertimbangkan bagaimana melakukan konservasi air pada musim kemarau. Pada musim kemarau, air sedapat mungkin dikonservasi agar tidak mengalir keluar dari sistem sehingga subsiden dan oksidasi gambut dapat diminimumkan. Dengan memahami komponen neraca air pada lahan gambut, khususnya di musim kemarau maka dapat dirancang cara-cara konservasi air yang lebih efisien pada musim kemarau.

Pada musim kemarau tinggi muka air di tengahtengah blok pertanaman kelapa sawit dapat mencapai 50 cm (Gambar 3). Pada kondisi ini tinggi muka air pada saluran sekunder dapat mencapai $70-80 \mathrm{~cm}$. Jarak saluran sekunder ke tempat pengukuran tinggi muka air di tengah blok adalah $150 \mathrm{~m}$ (Gambar 4).

Neraca air pada lahan gambut sangat dipengaruhi oleh sistem saluran yang sudah dibuat, debit drainase, drain spacing, dan konduktivitas hidrolik gambut. Dengan demikian persamaan steady-state Hooghoudt (ILRI, 1994) merupakan salah satu metode yang dapat digunakan untuk mengkaji neraca air lahan gambut, dimana kajian dilakukan menggunakan interval waktu yang sama, misalnya harian atau mingguan dengan asumsi masukan air (hujan-evapotranspirasi) pada setiap interval tersebut adalah konstan. Perhitungan komponen neraca air lahan berdasarkan persamaan Hooghoudt memerlukan besaran parameter berikut: a) Beda tinggi muka air di saluran dan titik piezometer (h), b) Konduktivitas hidrolik (K), c) Kedalaman ekivalen lapisan dibawah level saluran drainase (d), e) Drain discharge (q), dan f) Jarak saluran drainase- drain spacing (L). 


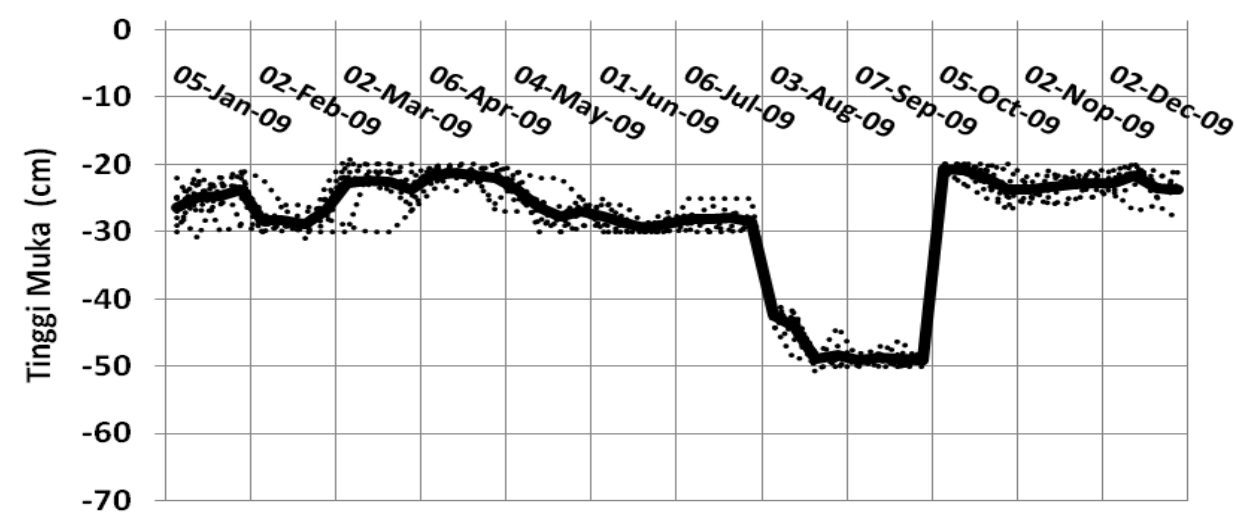

Gambar 3. Fluktuasi tinggi muka air di lokasi penelitian

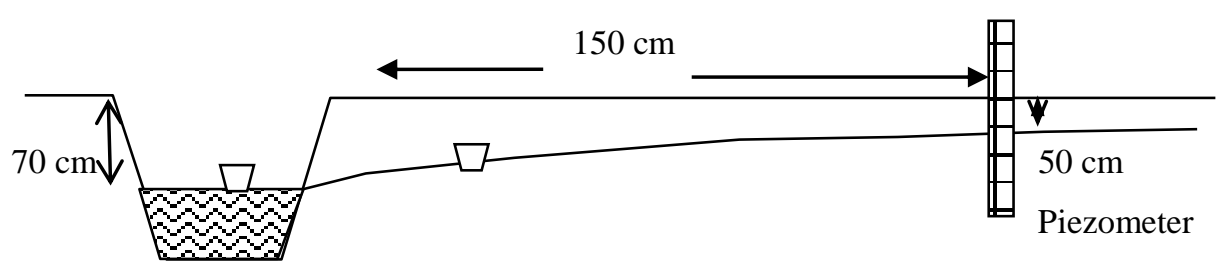

Gambar 4. Posisi piezometer dari saluran sekunder

\section{Konduktivitas hidrolik gambut (K)}

Jumlah air yang keluar sebagai drainase sangat tergantung kepada konduktivitas hidrolik. Konduktivitas hidrolik di lahan gambut, dimana muka air tanah dangkal dapat diukur dengan menggunakan metode Auger hole. Disamping pengukuran di lapangan penetapan konduktivitas hidrolik dapat dilakukan dengan menggunakan persamaan (1). Jika menggunakan persamaan (1) maka perlu diketahui nilai q (drain discharge). Mengingat tinggi air pada saluran tersier pada musim kemarau sangat kecil dan desain lereng saluran yang tidak uniform pada lokasi penelitian, air sering tidak dapat mengalir pada saluran tersier. Dalam keadaan ini sukar menghitung parameter yang diperlukan untuk menghitung debit air yang keluar dari weir (q), sehingga nilai q tidak dapat ditetapkan dengan cara ini. Nilai K pada penelitian ini diambil dari literatur berdasarkan penelitian Wangsadiputra (2005) yaitu sebesar $7 \mathrm{~m} \mathrm{hari}^{-1}$.

\section{Tinggi Muka Air}

Kematangan gambut pada lokasi Tj. Paring merupakan campuran hemik dan saprik, sedangkan pada lokasi Medangsari termasuk kategori saprik yang sudah lanjut. Rataan tinggi muka air (Piez Tj. Paring dan Piez Md. Sari) dan curah hujan pada bulan bersamaan dicantumkan pada Gambar 3. Seperti terlihat pada Gambar 3 tinggi muka air pada musim kemarau mencapai $50 \mathrm{~cm}$ ditengah-tengah blok tanaman kelapa sawit. Tinggi muka air di $\mathrm{Tj}$. Paring (Piez $\mathrm{Tj}$. Paring) yang pada grafik ditunjukan oleh dotted bar umumnya lebih tinggi sedikit dibandingkan dengan tinggi muka air di Medangsari (Piez Md. Sari) yang pada grafik ditunjukkan oleh hollow bar. Hal ini diperkirakan pengaruh dari perbedaan kematangan gambut di dua lokasi tersebut. Kematangan gambut di lokasi $\mathrm{Tj}$. Paring sebagian termasuk kategori hemik. Konduktivitas hidrolik gambut hemik lebih tinggi dari saprik.

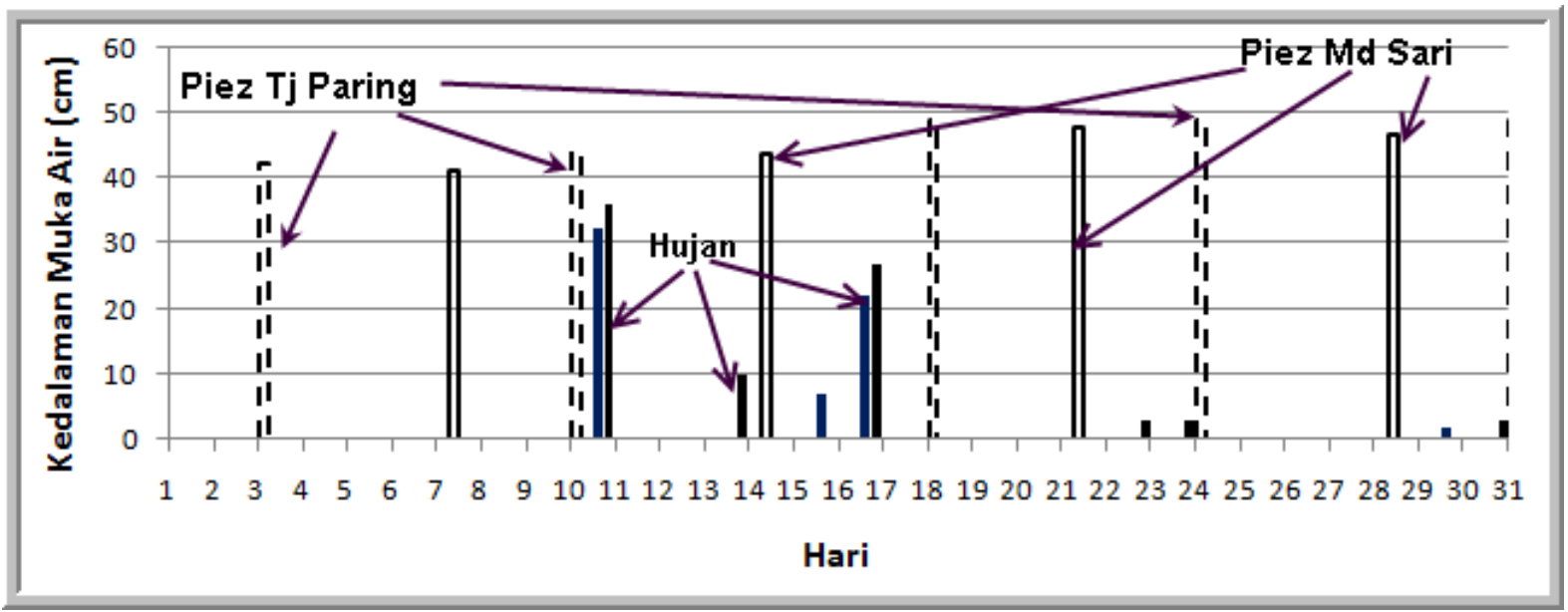

Gambar 5. Data curah hujan dan piezometer pada musim kemarau (Agustus Tahun 2009) 
Fakta lain yang terlihat dari data pada Gambar 5 adalah turunnya hujan pada tanggal 11 di kedua lokasi sebesar 32-35 mm (solid bar) tidak mampu mempengaruhi tinggi muka air di lahan gambut yang diukur pada hari berikutnya yaitu tanggal 14 dan 18. Curah hujan tersebut habis terevaporasikan ataupun sebagian hilang sebagai drain discharge sehingga tidak berkontribusi menaikan tinggi muka air. Kondisi ini umum terjadi dimusim kemarau (Juli-September) dimana curah hujan < evapotranspirasi sehingga menyebabkan tinggi muka air pada saluran tersier dapat mencapai 0 (nol).

\section{Debit drainase (q)}

Penelitian ini dilakukan pada musim kemarau. Pada saat musim kemarau, kedalaman air pada saluran (D) cukup kecil dan kondisinya seringkali hanya macakmacak. Dengan demikian persamaan Hooghoudt (persamaan 1) di atas dapat diubah menjadi:

$$
q=-\frac{4 \mathrm{Kh}^{2}}{\mathrm{~L}^{2}}
$$

Jarak saluran drainase (L) yang digunakan adalah jarak saluran tersier karena saluran sekunder cukup jauh dari posisi piezometer yaitu $150 \mathrm{~m}$. Jarak saluran tersier (L) adalah $30 \mathrm{~m}$. Berdasarkan data piezometer, rataan tinggi muka air di tengah blok adalah masing-masing 0.48 dan $0.45 \mathrm{~m}$. Beda tinggi muka air pada saluran tersier dengan muka air pada titik pengukuran piezometer (h) adalah berkisar diantara $15-20 \mathrm{~cm}$. Dalam hal ini kedalaman saluran tersier lebih dangkal dari $1 \mathrm{~m}$. Berdasarkan kondisi ini maka nilai q dapat dihitung dengan persamaan (2). Hasil perhitungan nilai q dicantumkan pada Tabel 1 .

Rataan drain discharge pada musim kemarau (Juli-September) sangat kecil yaitu $1 \mathrm{~mm}$ hari $^{-1}$. Besarnya drain discharge ini sangat dipengaruhi oleh nilai L (drain spacing) saluran. Dengan demikian, dalam rangka membuat desain saluran perlu diperhatikan agar L tidak memicu drain discharge yang berlebihan.

\begin{tabular}{|c|c|c|c|c|c|c|c|}
\hline \multirow{2}{*}{$\begin{array}{c}\text { Jenis } \\
\text { Gambut }\end{array}$} & \multirow[t]{2}{*}{$\begin{array}{c}\mathrm{K} \\
\left(\mathrm{m} \text { hari }^{-1}\right)\end{array}$} & \multicolumn{2}{|c|}{$\begin{array}{c}\text { Drain } \\
\text { spacing }(\mathrm{m})\end{array}$} & \multirow{2}{*}{$\begin{array}{l}\text { Piezo } \\
\text { meter } \\
(\mathrm{m})\end{array}$} & \multirow{2}{*}{ (m) } & \multicolumn{2}{|c|}{$\begin{array}{c}\mathrm{q} \\
\left(\mathrm{mm} \text { hari }^{-1}\right)\end{array}$} \\
\hline & & $\mathrm{L}_{30}$ & $\mathrm{~L}_{50}$ & & & $\mathrm{q}_{30}$ & $\mathrm{q}_{50}$ \\
\hline $\begin{array}{c}\text { Saprik / } \\
\text { Hemik }\end{array}$ & 7 & 30 & 50 & 0.48 & 0.20 & 1.3 & 0.4 \\
\hline \multirow[t]{2}{*}{ Saprik } & 7 & 30 & 50 & 0.45 & 0.15 & 0.7 & 0.3 \\
\hline & \multicolumn{5}{|c|}{ Rataan } & 1.0 & 0.35 \\
\hline
\end{tabular}

Tabel 1. Nilai q pada berbagai jenis gambut

\section{Ruang Pori drainase $(\mu)$}

Ruang pori drainase pada lokasi penelitian dihitung dengan membandingkan jumlah curah hujan yang jatuh dan kenaikan tinggi muka air pada piezometer. Berdasarkan data beberapa kejadian hujan dan kenaikan tinggi muka air pada diperoleh nilai ruang pori drainase seperti pada Tabel 2 .
Tabel 2. Nilai ruang pori drainase $(\boldsymbol{\mu})$

\begin{tabular}{lccc}
\hline Tanggal pengukuran & $\begin{array}{c}\text { Jumlah } \\
\text { hujan }(\mathrm{mm})\end{array}$ & $\begin{array}{c}\text { Kenaikan muka } \\
\text { air }(\mathrm{mm})\end{array}$ & $\begin{array}{c}\text { Ruang } \\
\text { pori } \\
\text { drainase }\end{array}$ \\
\hline 15 Januari 2010 & 29 & 60 & 0.5 \\
16 April 2010 & 82 & 110 & 0.7 \\
02 Juli 2010 & 57 & 110 & 0.5 \\
29 Oktober 2010 & 46 & 65 & 0.7 \\
12 Pebruari 2010 & 61 & 85 & 0.7 \\
18 Juni 2010 & 67 & 80 & 0.8 \\
02 September 2010 & 72 & 100 & 0.7 \\
30 Oktober 2010 & 44 & 90 & 0.5 \\
2 Juli 2010 & 66 & 90 & 0.7 \\
\hline
\end{tabular}

Jika ruang pori drainase 0.7 maka sebesar $30 \%$ dari volume gambut terdiri dari bahan padatan yang tidak dapat diisi air sehingga kenaikan muka air menjadi lebih tinggi dari jumlah curah hujan yang jatuh pada tempat tersebut. Adapun besar kenaikan tersebut adalah sebesar $30 \%$ x jumlah curah hujan (mm). Semakin besar nilai ruang pori drainase maka semakin sedikit padatan gambut dan semakin kecil kenaikan muka air akibat turunnya curah hujan.

\section{Neraca air}

Komponen neraca air di kebun kelapa sawit ditentukan dengan menggunakan persamaan (3). Besaran masing-masing parameter dapat dilihat pada Tabel 3.

$\mathrm{Ea}=\mathrm{R}-\mathrm{q}-\left(\mathrm{h}_{\mathrm{t}}-\mathrm{h}_{\mathrm{t}-1}\right) \mu$

Dimana:

$\mathrm{h}=$ Beda tinggi muka air di saluran tersier dan titik piezometer

$\mathrm{Ea}=$ Evapotranspirasi aktual $(\mathrm{mm})$

$\mathrm{R}=$ Curah hujan ( $\mathrm{mm})$

$\mathrm{q}=$ Drain discharge $\left(\mathrm{mm}\right.$ hari $\left.^{-1}\right)$

$\mu=$ Ruang Pori drainase

Data piezometer dikumpulkan setiap interval 7 hari (1 minggu), dengan demikian perhitungan neraca air ini menggunakan time step 7 hari.

Berdasarkan perhitungan menggunakan komponen neraca air, evapotranspirasi tanaman kelapa sawit yang ditanam pada gambut pada musim kemarau mempunyai rataan $4.2 \mathrm{~mm}$ (Tabel 3). 
Tabel 3. Perhitungan evapotranspirasi menggunakan parameter neraca air

\begin{tabular}{|c|c|c|c|c|c|c|c|}
\hline \multirow{3}{*}{ Waktu } & \multirow[t]{2}{*}{$\mathrm{h}_{\mathrm{t}}$} & \multirow[t]{2}{*}{$\mathrm{h}_{\mathrm{t}-1}$} & \multirow[t]{2}{*}{$\mathrm{R}$} & \multirow[t]{2}{*}{ q } & \multirow[t]{2}{*}{$\mu$} & \multicolumn{2}{|c|}{$\mathrm{Ea}$} \\
\hline & & & & & & 7 hari & 1 hari \\
\hline & $\mathrm{cm}$ & $\mathrm{cm}$ & $\mathrm{mm}$ & ${\text { mm } \text { hari }^{-1}}^{1}$ & & $\mathrm{~mm}$ & $\mathrm{~mm}$ \\
\hline 14-21 Agustus 2009 & 43 & 49 & 37 & 1 & 0.7 & 29.0 & 4.1 \\
\hline 14-21 Agustus 2009 & 45 & 46 & 37 & 1 & 0.7 & 27.5 & 3.9 \\
\hline 03-10 Juli 2009 & 46 & 51 & 40 & 1 & 0.7 & 30.5 & 4.4 \\
\hline 03-10 Juli 2009 & 46 & 49 & 40 & 1 & 0.7 & 31.1 & 4.4 \\
\hline 07-14 Agustus 2009 & 42 & 43 & 46 & 1 & 0.7 & 32.2 & 4.6 \\
\hline 07-14 Agustus 2009 & 45 & 46 & 46 & 1 & 0.7 & 34.2 & 4.9 \\
\hline 21-27 Juli 2009 & 29 & 30 & 37 & 1 & 0.7 & 25.5 & 3.6 \\
\hline 14-21 Agustus 2009 & 45 & 49 & 37 & 1 & 0.7 & 29.6 & 4.2 \\
\hline \multicolumn{7}{|c|}{ Rataan } & 4.2 \\
\hline
\end{tabular}

Tabel 4. Neraca air selama musim kemarau (juli -september) untuk panjang saluran $30 \mathrm{~m}$ dan $50 \mathrm{~m}$

\begin{tabular}{cllcc}
\hline Proses & & Komponen & Juli - September 2009 & Total \\
\hline \multirow{2}{*}{ INPUT } & Rainfall & & $311 \mathrm{~mm}$ & $451 \mathrm{~mm}$ \\
& Pre-Storage & & $140 \mathrm{~mm}$ & \\
& & & $90 \mathrm{~mm}$ & $476 \mathrm{~mm}$ \\
\multirow{2}{*}{ OUTPUT } & Drain Discharge (q) & Drain spacing $=30 \mathrm{~m}$ & $31 \mathrm{~mm}$ & $417 \mathrm{~mm}$ \\
& & Drain spacing $=50 \mathrm{~m}$ & $386 \mathrm{~mm}$ & \\
& & & & \\
\hline
\end{tabular}

Dengan menggunakan parameter yang sudah ditentukan di atas, dapat dihitung neraca air selama musim kemarau seperti tertera pada Tabel 4. Pada musim kemarau komponen yang termasuk sebagai sumber (input) air adalah curah hujan dan pre-storage air yang berasal dari bulan sebelumnya. Nilai pre-storage ini adalah besaran kolom air sebelum memasuki musim kemarau. Berdasarkan Gambar 1, nilai pre-storage yang diambil pada penelitian ini adalah $20 \mathrm{~cm}$. Nilai kolom harus dikalikan dengan besaran pori drainase $(\mu)$ untuk memperoleh jumlah air yang digunakan pada perhitungan neraca air. Sementara itu komponen output terdiri dari drain discharge (q) sebesar $90 \mathrm{~mm}$ pada kondisi eksisting (L=30 m) dan $31 \mathrm{~mm}$ jika L diperpanjang menjadi $50 \mathrm{~m}$. Drain discharge ini terjadi pada awal bulan musim kemarau (Juni-Juli) dimana tinggi muka air $<40 \mathrm{~cm}$. Total evapotranspirasi selama Juli-September sebesar $387 \mathrm{~mm}$. Perbandingan komponen output dan input ini menghasilkan defisit air sebesar $25 \mathrm{~mm}$ per 3 bulan pada panjang drain spacing (L) $30 \mathrm{~m}$. Jika nilai L diperpanjang menjadi $50 \mathrm{~m}$ maka terdapat surplus sebesar $34 \mathrm{~mm}$. Namun surplus hanya dapat meningkatkan tinggi muka air $23 \mathrm{~mm}$ atau $2.3 \mathrm{~cm}$ dari kondisi eksisting yang berada pada level $40-50 \mathrm{~cm}$. Dengan demikian masih perlu usaha lain untuk meningkatkan tinggi muka air. Usaha-usaha lain yang dapat dilakukan adalah meningkatkan pre-storage dan membuat cascaded stop-log pada jaringan saluran.

\section{SIMPULAN}

Persamaan Hooghoudt dapat digunakan menentukan komponen yang mempengaruhi neraca air pada tanah gambut yang ditanami kelapa sawit. Pada musim kemarau (selama Juli-September) jumlah evapotranspirasi adalah $386 \mathrm{~mm}$. Jumlah ini jauh melampaui jumlah curah hujan pada kurun waktu tersebut sebesar $311 \mathrm{~mm}$. Drain dicharge pada kurun waktu ini sebesar $90 \mathrm{~mm}$ atau $1 \mathrm{~mm}$ hari $^{-1}$. Berdasarkan neraca air tersebut terdapat defisit sebesar $25 \mathrm{~mm}$ per 3 bulan. Jika drain spacing ditingkatkan menjadi $50 \mathrm{~m}$, drain discharge berkurang menjadi $31 \mathrm{~mm}$ sehingga terjadi surplus neraca air $34 \mathrm{~mm}$ lapangan. Namun surplus hanya dapat meningkatkan tinggi muka air sebesar $2.3 \mathrm{~cm}$ dari kondisi aktual yang berada pada level $40-50 \mathrm{~cm}$.

\section{SARAN}

Dengan demikian masih perlu usaha lain untuk meningkatkan tinggi muka air, misalnya meningkatkan pre-storage dan menjaga supaya tidak terjadi drain discharge sama sekali dengan membuat cascaded stop-log pada saluran drainase yang dilapisi dengan plastik.

\section{DAFTAR PUSTAKA}

Badrun, M. 2010. Lintasan 30 Tahun Pengembangan Kelapa Sawit. Direktorat Jenderal Perkebunan, Kementerian Pertanian dan Gabungan Pengusaha Kelapa Sawit Indonesia.

\section{ICALRD. 2010. Policy Brief: Kajian Pemanfaatan Lahan} Gambut untuk Pengembangan Perkebunan. Ministry of Agriculture, Indonesia.

ILRI. 1994. Drainage principles and applications. Nr. 16/2nd ed. International Institute for Land Reclamation and Improvement, Wageningen, The Netherlands. 
Noor, M. 2010. Peningkatan produktivitas Lahan Gambut dan perluasan lapangan Kerja. Prosiding Seminar Lokakarya Nasional Pemanfaatan Lahan Gambut Berkelanjutan untuk Pengurangan Kemiskinan dan Percepatan Pembangnunan Daerah. PSP-DITSLIPB Bogor.

Ritzema, H.P. 2007. The Role of Drainage in The Wise use of Tropical Peatlands. Alterra ILRI, Wageninge University and Research Centre, AA Wageningen, The Netherlands.

Sabiham, S. 2000. Kadar air kritis gambut Kalimantan Tengah dalam kaitannya dengan kejadian kering tidak balik (Critical water content of the Central
Kalimantan peats in relation to the process of irreversible drying). J. Tanah Trop., 11: 21-30.

Sabiham, S. 2010. Desain pengelolaan Lahan Gambut dalam mendukung produktivitas pertanian berdasarkan teladan selama tiga dekade (19702000). Prosiding Seminar Lokakarya Nasional Pemanfaatan Lahan Gambut Berkelanjutan untuk Pengurangan Kemiskinan dan Percepatan Pembangnunan Daerah. PSP-DITSL-IPB Bogor.

Wangsadiputra, M. 2005. Analisis hidraulik aliran bawah permukaan melalui media gambut di Guntung-Riau. J. Teknik Sipil, 12: 21-34. 